the drainage tract. One case is also recorded in the table with the remark, "guérison, fistule?" Obviously, the number of cases thus far reported is too small for statistical study, yet one is irresistibly impressed with the favorable results in the cases in which sutures were not applied. So that Dr. Glantenay's arguments are in a measure, actually confuted by his own statistics.

The rare longitudinal wounds of the aseptic ureter occurring in the course of transperitoneal operations must be disposed of by suture, if possible. But if the duct is not readily accessible for this purpose, drainage through a posterior incision may be required.

Certainly we have much to learn on the subject of longitudinal wounds of the ureter: but our knowledge can now be advanced by clinical experience alone. Meantime we should be careful to properly estimate the value of the materials already at hand.

Dr. Konrad Buedinger ${ }^{3}$ has recently discussed complete transverse injuries of the ureter, detailing the methods of Poggi and of the present writer for the reunion of the duct after such traumatisms. Dr. Buedinger tried the method of Poggi upon a dog. This method, it will be remembered, consists in the end-in-end invagination of the upper ureteral fragment into the lower. To do this by means of a traction suture was found so difficult that he gave up the effort. For, in the first place, the invagination would not succeed, since the upper end always slipped out of the lower end as soon as peristaltic action occurred, and, in the second place, the ureter was stretched too much transversely. Becoming discouraged with Poggi's method, Buedinger gave up experiments in this line. If he had tried the writer's method by lateral implantation of the upper end of the ureter into a slit in the lower portion of the tube, these objections would have disappeared.

Glantenay describes the writer's method so fully and clearly that he evidently understands it, but at last discards the procedure utterly, evidently influenced by the paper of Buedinger, since he mentions no experience of his own. His sole objection to the method lies in the fear that the invagination suture (by which the upper end of the ureter is drawn into the slit in the side of the lower portion) may be left in the ureter and may form a nidus for the formation of a concretion. This theoretical objection is wholly refuted by the fact that this suture does not need to pass through the mucosa of the upper fragment, the muscular and connective tissue layers of the duct being thick and strong enough to give substantial hold for the thread. It must also be remembered that the catgut suture would at first be likely to bury itself by cutting deeper and deeper into the walls of the ureter, and later on would be absorbed completely.

Glantenay coolly states that the case operated upon by the writer's method by Dr. H. A. Kelly, "does not seem rigorously demonstrative. If it proves the harmlessness of the maneuvers which this complex procedure necessitates, its efficacy is not evident to us, for where is the proof of the reëstablishment of the course of the urine by the injured ureter?"

The child-like naivété of this inquiry almost disarms one. Yet perhaps we should take him seriously, especially as he complains that he could not find the detailed report of the case, a statement which would seem to imply that he did not have access to the In-

\footnotetext{
3 Archiv. für Klinische Chirurgie Bd. XLviı, H. 3.
}

dex Medicus and the Annals of Surgery even in Paris. The proof which he desires lies in the following facts: 1 , no urine escaped through the abdominal drain leading down to the site of injury; 2 , no accumulation of urine in the peritoneum or symptoms of resorption were noted; 3 , a normal quantity of urine was passed and no symptoms of ureteral obstruction occurred.

It may be added that Dr. Doherty of Georgia, has sent the writer a very brief account of a similar case, in which he accidentally cut the ureter across during a laparotomy and immediately closed the injured duct by the same method. His patient recovered without an untoward symptom.

103 State Street.

\section{THE INFILTRATION METHOD OF ANESTHE-} SIA IN OPHTHALMIC PRACTICE.

Read in the Section on Ophthalmology, at the Forty-sixth Anuual Meeting of the American Medical Association, at Baltimore, Md., Mav 7-10, 1895 .

BY H. V. WÜRDEMANN, M.D.

Director and Secretary Wisconsin Geveral Hospital Association : Oculist and Aurist to the Children's Hospital. the Mil watake County Hospital for Chronic Insane, and to the Elms Hospital Instructor in Eye, Lar and Throat, Elm Hospital; Secretary Section on ophthalmology American Medi. (al Association. MILWAUKEE, WIS,

Just six months ago we brought to the notice of the medical profession our $\mathbf{r}^{1}$ conclusions obtained by following out the line of experiments instituted but a few months before by Schleich, ${ }^{2}$ of Berlin, relative to the anesthetic properties of water, and its application in surgical practice. The experimental stage has been passed and we are now able to substan. tiate some of his statements made in our first article which at that time were not yet proved.

A brief resumé of Schleich's experiments may be advisable: this investigator was employed in research for the production of a better and less harmful method of local anesthesia than that which has hitherto obtained. He first experimented with hypodermatic injections of cocain and other drugs, finding that a 2 per cent. solution of cocain was the weakest. which would produce anesthesia when introduced beneath the skin. A couple of syringefuls of this solution would be the toxic dose and such an amount would be necessary in many trivial operations. It is well known that cocain injection is dangerous to life and even small quantities of the drug may give rise to very unpleasant symptoms.

Our investigator discovered that by injecting the solution into but not under the skin in the surprisingly small quantity of .002 to 1.00 , a practical anesthesia would result throughout the whole thickness of the skin and insensibility more profound than that by hypodermatic injection of a solution one hundred times this strength could be obtained. The logical deduction followed that the drug itself could not be the main agent in causing the anesthesia. Injections of distilled water were tried and produced anesthesia but these were painful, $i . e$. , the infiltration of the water into the skin produced a burning pain which transcended that of the knife. Complete anesthesia, however, followed the infiltration.

Could it be the infiltration alone that produced the pain of injection and later obtunded the sensibil-

1"Explanation and Demonstration of the Infiltration Method of An esthesia." JoURNA I. AMERICAN MEDICAL A ssocIATION, Dec. 29, 1894. 2 Schleich, "Schmerlose Operationen," Berlin, 1894. 
ity? Injections of the normal salt solution (.6 per cent.) were made but no anesthesia followed, yet the injection itself was painless. The proposition to be solved then was as follows: if infiltration of water alone into the tissues produced pain followed by complete anesthesia, while the injection of .6 per cent. sodium chlorid was painless but made no alteration in the sensibility of the nerve ends, there must be between these two extremes a salt solution of a certain strength which would at the same time be so similar to the normal fluid of the blood as to cause little or no pain in infiltration and yet be sufficiently like water to produce anesthesia of the parts so injected. Experiments proved that a .2 per cent. salt solution met these requirements. Solutions above or below these strengths were either painful to inject or produced no anesthesia. Operations may be painlessly done by a .2 per cent. salt solution. I have personally experimented with various fluids: the ethers and alcohols are similar to water in that they cause burning pain on injection, followed later by anesthesia. Ether, however, produces capillary hemorrhage and alcohol coagulates the albumin of the tissues and both substances, aside from this, are too irritative to be of use in this method. The various oils are not painful to inject but afford no anesthesia. They are usually absorbed without producing material change in the tissues.

Cocain .2 per cent., morphin .2 per cent., ac. carbol .2 per cent., bromid of potassium 3 per cent., methyl violet 1 per cent., caffein 2 per cent., sugar 3 per cent., and other substances in aqueous solution were found to allow of the anesthetic action of water upon the nerve nilaments. The anesthetic drugs, cocain, ac. carbol, and morphin have a special characteristic: $i . e$, their addition in very small quantities to the .2 per cent. salt solution prevented the paresthesia incident to injection of simple saline solution and the infiltration of inflamed or hyperesthetic areas could be made without pain.

The narcotics were more active when used in the .2 per cent. salt solution and could be used in even lower attenuations, for instance, .01 per cent. cocain in a .2 per cent. salt solution prevented paresthesia. It was also found that if the solutions were used cold, their efficacy was increased many fold, and that when used at the temperature of the body, little or no anesthesia followed.

The following formulas are advocated by Schleich $:^{3}$

B Cocain mur. . . . . . . . . . . . . . 20

Morph.mur . . . . . . . . 025

Natr. chlor.............. . . 20

Aqu. dest. ad . . . . . . . 100

M. Sterilisat. adde. sol. ac. carbol. 5 per cent. gtt $i j$.

S. Solution No. 1, strong. For operation upon highly inflamed or hyperesthetic areas.

B Cocain mur. . . . . . . . . . . . 10

Morph.mur . . . . . . . . . . . 025

Natr. chlor.

Aqu. dest. ad . . . . . . . . . 100

M. Sterilisat. adde ac. carbol. 5 per cent. gtt ij.

S. Solution No. 2 , medium. For most operations.

$\mathrm{B}$ Cocain mur.

Morph. mur .

Natr. chlor. .

Aqu. dest. ad

\section{1}

005

$100 \overbrace{}^{20}$

M. Sterilisat. adde. sol. ac. carbol. 5 per cent. gtt ij.

$\mathrm{S}$. Solution No. 3, weak. For superficial operations upon nearly normal tissues.

3 The "keeping" qualities of these solutions are Improved by the addition of a few drops (gtt jji) of a 5 per cent. solution of trikresol as recommended by Parke, Davis \& Co.
At my request, Parke, Davis \& Co., of Detroit, Mich., have prepared tablets, triturates and compressed tablets from which these solutions may be extemporaneously made by dissolving one tablet in 100 cubic centimeters ( $\xi_{i i j}$ ) of distilled or boiled water. These will be found convenient in practice.

All are to be kept strictly sterile; glass stoppers or scorched cotton such as are used in bacteriologic experiments for the bottles; small quantities to be poured out in smaller vessels for each operation. Just before operation the solution should be cooled by laying the bottle containing it on ice. The common form of hypodermatic syringe with the finest of needles is all that is usually needed. Dr. Chas. Denison of Denver, Colo., has given us an aseptible syringe of larger capacity, with piston packing of asbestos which is particularly applicable for aseptic injection. The syringe is kept in good order by being frequently soaked in a 5 per cent. carbolic solution and the needle sterilized after each operation.

The discovery of these truths so valuable for the question of local anesthesia is due simply to a slight change of method; the application of the solution within and not under the skin. The anesthesia is caused by the replacement of the normal fluids of the tissues by a fluid of less specific gravity (the water) which causes anemia, compreseion and̈ cool-

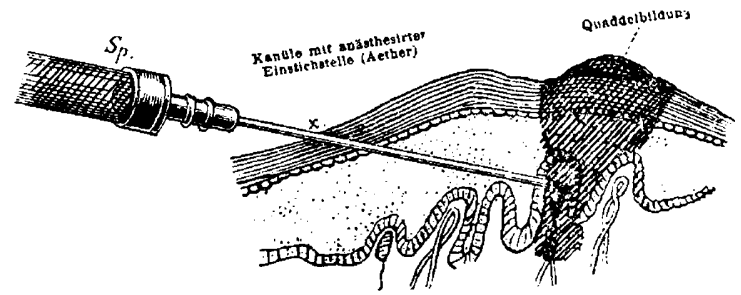

FIG. 1.-Diagram of a section of the skin, showing formation of the first wheal.

ing, producing thereby a temporary paralysis of the nerve filaments. The pain of the infiltration of indifferent solutions is abolished by the minute doses of narcotic drugs, (morph. cocain, carb. ac.).

It is perhaps well to here go into the technique of the production of local anesthesia by this method. The field of operation is made aseptic in the usual manner. Having the required formula, the solution aseptic and cold, we fill the sterilized hypodermic syringe; pinching the skin slightly between the thumb and forefinger of the left hand; the needle is then passed obliquely under the epidermis to the papillæ, intra-cutaneously, until the lumen is fully inserted. A few dropsare then injected, thereby producing a white elevated wheal, the infiltration extending throughout the whole thickness of the skin. (See Fig. 1.) There is immediate and complete anesthesia throughout the extent of the infiltration which lasts from ten to twenty minutes according to the density of the tissue so edematized. The rieedle is then reinserted at the periphery of the wheal and the area infiltrated to the required extent and depth. No tissue offers any deviation from the dictum: every structure is made anesthetic that can be artificially edematized; this holds good for skin, mucous and gynovial membrane, periosteum,fascia, muscle, lymph glands, nerves, viscera, and even bone.

Anesthesia exists only within the area infiltrated by the solution and outside of that, normal sensation remains. In operations or or through the skin and mucous membranes the first wheal is increased to the size of a dime by increased pressure on the piston; 
the needle is moved and re-inserted at the periphery of the wheal, but still within it, and a new wheal raised. In this way the line of incision is marked out to any desired length or breadth. (See k'ig. 2.) In general surgical operations we would then infiltrate the underlying tissues, by slowly pushing in the needle and injecting a few drops at a time until the deeper tissue is edematized.

By cooling the spot selected for the formation of the first wheal by ether or rhigolene spray, or on $\mathrm{mu}$. cous membranes by touching the spot with a strong solution of carbolic acid or applying cocain, the first injection may be made, if so desired, without even feeling the prick of the needle. This is seldom neces. sary as a very fine needle may be inserted without pain even in very tender tissues such as the eyelids. The succeeding injections may now be made without causing sensation. There is no sensation to the infiltration proper.

Where the tissues are inflamed the sensibility is pathologically increased. Here it is indispensable

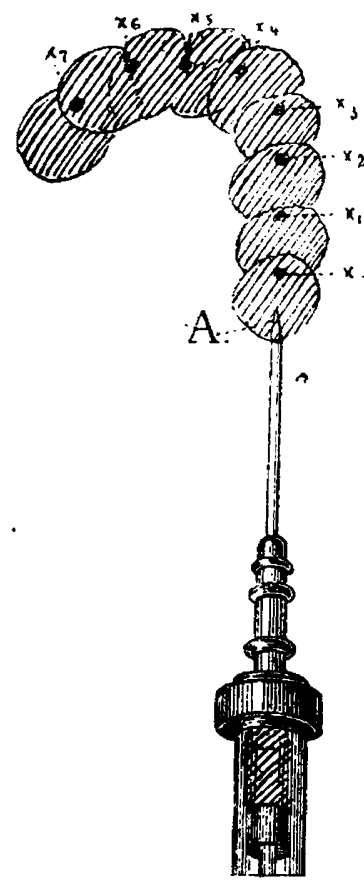

Fig. 2.-Formation of the cutaneous wheals. A, spot made anes thetic by ether spray for the first injection.

that the infiltration be begun in sound tissue and carried over into the part to be operated upon. (See Figs. 3-4.) The dilated blood and lymph channels of the inflamed skin allow us to anesthetize quite a large spot from one puncture.

The injection should be done slowly at first and when the infiltration ${ }^{-}$only felt by its tension we may rapidly flood the part to the required extent. Under no circumstances must fluid be primarily injected into an abscess, an exudation or a pathologic focus. The only result is increased tension and pain. We must not lose sight of the cardinal fact that the anesthesia exists only within the area infiltrated by these solutions and that outside of that there is normal sensation. The method rests principally on the production of a complete artificial edema of the tissues. Wherever we wish to operate with exact anesthesia, the field of operation must be tensely filled with the solution so that it exudes from the cut surface.
It should be remembered that our use of attenuated solutions of the narcotic drugs has nothing akin to the doctrine of the followers of the dogma "similia similibus," etc. These statements may be readily substantiated upon your own persons, as I have don $\theta$ many times on myself and other physicians. I need not call to your attention the well-known dangers of chloroform and ether anesthesia and the waste of the surgeon's time, the discomfort to the patient, and the necessity for skilled assistance. Cocain injection of the solutions of the usual strengths ( 5 to 10 per cent.) is certainly far more dangerous to life than the administration of chloroform. The higher solutions of cocain surely diminish the exudative process and retard the healing and, in some cases, actually destroy the trophic filaments so that gangrene has been known to occur. Nothing of the sort has been found to result from the infiltration of the solutions recommended in this article. Anesthesia is complete and occurs immediately and lasts long enough for almost any external operation. There is noobjection at any time to repeating the injection if feeling should return during the operation. Indeed, we might safely operate for hours upon a small area if so inclined. The advantages of the method are also evident from its simplicity, safeness and celerity.

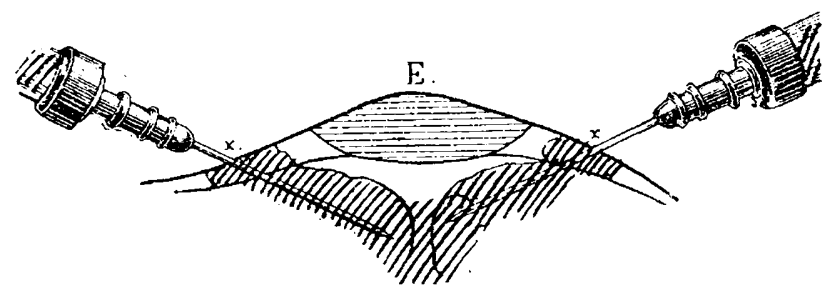

FIG. 3.-Infiltration of inflamed surfaces.

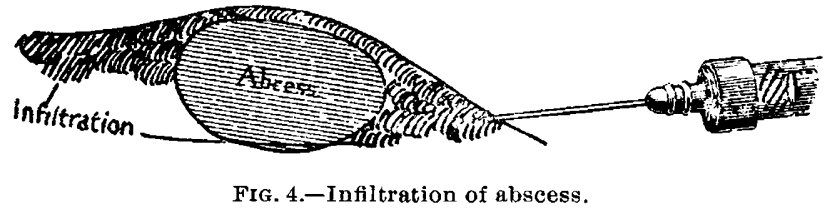

The method has gained credence and is now in common use by many busy practitioners. Operations have been done, from the removal of ovarian tumors and amputations down to the opening of boils without pain, and with satisfaction both to the physician and patient. I have personally done half a hundred operations upon the eyelids, etc., by this form of anesthesia, as well as various operations upon other parts of the body while prosecuting the investigation. My first operation was done upon a deep seated felon. I have assisted at a number of circumcisions, excisions of tumors, and minor operations, making the injections myself; I have had reports from many surgeons in different portions of the United States of its use for operations varying in severity from ingrowing toe-nail to hernia, in which the anesthesia has been satisfactory. Healing has been by first intention and in only three instances have we had reports in which it has been delayed."

In the foregoing, I have purposely said little about its use in ophthalmic practice, leaving this to be inferred from what I have said concerning minor surgical procedures in other localities. Indeed, infiltration anesthesia is of greater value to the general

4 ln one of these, an operation for removal of tumor in axilla, the pa tient used the arm freely after the operation. In the other two, the patients were scrofulous and bealing would have probably followed the same course if a general anesthetic had been given. 
practitioner and surgeon than to the oculist, as the instillation of cocain into the eye is sufficient for most of our operations. For obvious reasons this method is applicable only to operations in our practice upon the eyelids, etc. The resultant edema would interfere with most operations within the orbit such as enucleation.

However, I bring the subject to workers in ophthalmic surgery, believing it will be an advantage to the ophthalmic surgeon for most operations in which instillation of cocain is inapplicable, but which may be deemed too trivial for a general anesthetic and yet are attended with considerable pain. In my practice it is in daily use for chalazia, tarsal tumors, opening of abscesses and plastic operations. For most office operations the Schleich method is an invaluable contribution to our therapeutics. It should do away with the injection of dangerous solutions of cocain and take the place of general anesthesia for many operatious.

The technique of the injection was then shown upon the arm of one of the ophthalmologists there present after which by the kindness of Dr. Harry Friedenwald, of Baltimore, a patient was shown with two sebaceous cysts of the forehead. Dr. Würdemann injected the skin covering of this tumor with solution No. 1 and the growths were dissected out by a surgeon, without the patient experiencing the slightest pain or feeling either the injection or the operation. Six stitches had to be taken in the wound of the larger, and two in that of the smaller growth.

805 Grand Avenue.

\section{REPORT OF COMMITTEE ON EXAMINATION} AND CARE OF EYES DURING SCHOOL LIFE-INSTRUCTION OF TEACHERS AND SCHOOL AUTHORITIES AND LEGAL PROVISIONS.

Read in the section on Ophthalmology at the Forty-sixth Annual Jeeting of the American Medical Association, at Baltimore, Md. May $7-10$, $189 \overline{5}$

B. ALEX. RANDALI, Chatrman. PHII,ADELIHIA, PA.

Mr. Chairman and Gentlemen:-Your Committee in approaching the subject assigned to them. find themselves of one mind in advocating advance in this important field of preventive medicine; but can less easily concur upon the exact lines within which they deem it practicable to advise action at the pres. .ent time. Located in cities of various sizes and widely separated portions of the country, the environment of each member must react distinctly upon his view of what it is judicious to attempt, for it is practically self-evident that the popular mind is but little prepared for any active steps in the matter, and that it will be very unwise to take a position too advanced to secure the indorsement of reasonable men, medical and lay. Public opinion alone can carry this project through; and even in the professionnay, even among our ophthalmic colleagues-this opinion has still largely to be shaped. Our steps must be guarded, therefore; yet they need not be timid nor indecisive. We must form the advance guard, sure that the rank and file will lag behind the standard which we place before them, however wisely chosen. Let us look, then, not for our idea of the maximum now everywhere practicable, but rather for the minimum that can be held efficient and satisfactory.

The opposition likely to be encountered in our efforts to advance the cause will come primarily, perhaps, from professional jealousy rather than from school inertia or individual restiveness and assertion of freedom. That too many men intrusted with such investigations may try to coin profit to themselves from them, must be conceded; yet we contend that still more men of the first rank will refuse, or will hesitate to accept, such a trust because of the unworthy motives likely to be gratuitously imputed to them. In our noble profession there are hundreds capable and willing to take up this or any other selfsacrificing task with no thought of personal exploitation-finding their sole rewards in the knowledge thus gained and the beneficent work accomplished. There may be exceptions among those who have already wrought in this field; but we know of none. Yet any one of us in offering to do such work in his own community gratuitously, much more if claiming compensation, would be very careful to whom he broached his proposition, knowing how probably he would be misconstrued.

Let us deal frankly and fairly with this matter, individually leaving its execution wholly alone, if we have not the interest or can not afford to undertake it without more compensation than is likely to be given-and leave others unhampered by any insinuation of baser motives in being willing to carry forward the needed work.

The next line of obstruction is to be found in the school authorities. The cramming process now in vogue demands more time than can be found; so they will grudge every minute that is given to medical examinations. Inl-paid as are most of our teachers, they will at times demur to taking more work on their shoulders, or that any of the scanty school funds should be diverted to paying medical examiners. School discipline is apt to suffer in being broken in upon by such investigations: and some will fear, like the parents, lest we "put notions in the children's heads." An officially constituted group of "lame ducks" for whom forward seats, special illumination or lightened burdens would be required, is an incubus from which some would gladly escape.

Yet it is but just to another noble and valuable class in our midst to insist that the great majority of teachers will cheerfully, if not enthusiastically, hail the promise of better ocular hygiene for their pupils and make any reasonable sacrifice to do or to permit the good work. As a body they will welcome any system which will enable them to do all they can to obviate or relieve danger to their little charges. This spirit should be fostered; and they should be given test-cards and taught how to use them and make other examinations within tbeir scope; for muchall that is possible for some localities, perhaps-can be thus done through the agency of the teachers.

The scholars and their elders will occasionally offer opposition, regarding such examinations as invasions of their liberties. This will rarely occur unless provoked by some indiscretion or arbitrary order of the examiner or school authorities. Yet it can be avoided only by the most scrupulous bearing on the part of the investigator, not only in setting such a study on foot, but even when it is apparently progressing most favorably. An unwilling pupil may be gently ridiculed and passed over until in better frame of mind; any coercion is likely to prove disastrous in these delicate positions. The examiner should even be very cautious as to any leading questions and very chary of remarks as to his findings, generally declining to report in any but the official form. This had 